\title{
Fine mapping of wheat Tatyd with pleiotropic roles in plant architecture, leaf yellowish and improved powdery mildew resistance
}

\section{Heng Zhang}

Nanjing Agricultural University

\section{Yiming Chen}

Nanjing Agricultural University

\section{Ying Niu}

Nanjing Agricultural University

\section{Xu Zhang}

Nanjing Agricultural University

Li Sun

Nanjing Agricultural University

\section{Haiyan Wang}

Nanjing Agricultural University

Jin Xiao

Nanjing Agricultural University

Xiue Wang ( $\square$ xiuew@njau.edu.cn )

Nanjing Agricultural University https://orcid.org/0000-0002-6312-3417

\section{Research article}

Keywords: Wheat; Leaf color; Photosynthesis; Mapping

Posted Date: February 20th, 2020

DOI: https://doi.org/10.21203/rs.2.24038/v1

License: (c) (1) This work is licensed under a Creative Commons Attribution 4.0 International License. Read Full License 


\section{Abstract}

Background: Photosynthesis is the primary energy for biosphere, and is the foundation for life on earth. Leaf color mutations are widely used to study chloroplast structure and development, biosynthesis and metabolism of chlorophyll and plant photosynthesis, such as in rice and maize, with many genes be mapped and cloned. By comparison, there is few researches on the leaf color mutants in wheat. More and more studies have demonstrated that photosynthesis is involved in plant-pathogen interaction, whether leaf color mutations affect plant-pathogen interactions are rarely reported.

Results: In this study, a leaf color mutant, NAU31, which has fewer tillers, dwarfed plant and improved powdery mildew resistance was identified from regenerated plant of common wheat cv. Yangmai158. Inheritance analysis of NAU31 showed that the above mutant traits were significantly correlated and controlled by a dominant gene, named Tatyd. Linkage analysis of a mapping population between NAU31 and a synthesized wheat W7984 using SSR markers, the Tatyd was preliminary mapped to 2DS. By BSA and linkage analysis using a 55K wheat SNP array, the Tatyd was fine mapped to the terminal region of 2DS, flanked by markers ZH47 and gwm296 and corresponding to a physical interval of $0.76 \mathrm{Mb}$. Genome-wide gene expression analysis indicated that the impairing of photosynthesis may be responsible for plant yellowing in NAU31. Photosynthetic physiological analysis showed varied chloroplast inner structure in the mesophyll cells of the mutant, and this may lead to reduced chlorophyll content (chlorophyll "a", Chlorophyll "b", total chlorophyll and carotenoid), as well as decreased maximum quantum efficiency of photosystem II (Fv/Fm) and Net photosynthetic rate.

Conclusions: A mutant with few-tiller, plant yellowish, dwarfness and improved powdery mildew resistance was identified, and the mutated locus Tatyd was fine mapped to a $0.76 \mathrm{Mb}$ genome region of wheat chromosome 2D. The yellowing trait of NAU31 may be attributed to its reduced photosynthesis ability due to changes of the chloroplast inner structure. The cloning of Tatyd will facilitate dissection of the mechanism involved in chloroplast development of wheat and the regulation of plant development and disease resistance.

\section{Background}

Photosynthesis is the primary energy for biosphere, and is the foundation for life on earth [1]. More than $90 \%$ of crop biomass is derived from photosynthetic products, and the improvement of photosynthesis would undoubtedly increase crop yield [2]. Photosynthesis and translocation in relation to crop yield have been reviewed previously [3]. There is a positive correlation between photosynthesis and biomass and yield $[4,5]$. The relative growth rate of plant was positively correlated with daily integrals of photosynthesis expressed in different species and environments, and $93 \%$ of the variation in relative growth rate can be explained by photosynthesis [4], when yield increased by $27 \%$, maximum photosynthetic rate increased by $23 \%$ in wheat [5]. Increasing photosynthesis by changing the level of SBPase (Calvin-Benson cycle enzyme sedoheptulose1,7-biphosphatase) can increase wheat total biomass and dry seed yield [6], and sped up the adaptation of photosynthesis systems to light changes 
can also increase plant biomass [7]. Decreased photosynthetic electron transport rate of plants leads to reduced plant height and tiller number [8]. Recently, more and more studies have demonstrated that photosynthesis is involved in plant-pathogen interaction [9]. Decreased plant photosynthesis affect nutrient uptake and fungal development of obligate biotrophic fungi [10]. MPK3/MPK6 was reported to coordinate plant growth and disease resistance by regulating decreased photosynthetic capacity and upregulated expression of disease-related genes [11].

Phenotypic analyses of plants that are mutant for leaf color are widely used to investigate genes associated with plant photosynthesis, such as the biosynthesis and metabolism of chlorophyll (Chl), chloroplast structure and development [12]. The leaf color is mainly determined by $\mathrm{Chl}$ and carotenoid contents, in which $\mathrm{Chl}$ is the main photosynthetic pigment in plant [13], is responsible for light harvesting in the antenna systems and drives electron transport in the reaction centers [14]. The Chl biosynthetic pathway comprises about 20 different steps [15], and mutations in any of these steps can cause changes in the content and proportion of $\mathrm{Chl}$, which ultimately leads to leaf color phenotypic changes. The Photosynthesis occurs in chloroplasts of eukaryotes [16]. Chloroplast biogenesis and development requires a highly coordination of gene transcription, translation, protein renewal and metabolism. Multiple genes regulate these steps, and defects in any of these steps also lead to impaired chloroplast and leafcolor mutation [17, 18]. Leaf color mutants have been reported in rice (Oryza sativa) [19], maize (Zea mays) [20], barley (Hordeum vulgare) [21] and etc. In rice, over 200 leaf color genes have been mapped, and more than 50 have been cloned [19]. Among them, 24 and 19 genes are proved to participate in photosynthetic pigmentation and chloroplast development, directly or indirectly [19, 22]. In maize, among the cloned leaf color-related genes, elm1 [23], Oy1 [24] and elm2 [25] regulate Chlorophyll biosynthesis, while hcf60 [26], vyl [27] and ygl-1 [20] are related to chloroplast development.

Up to now, only a few leaf color mutants have been reported in wheat, such as Neatby's virescent [28], CD2, CD3 and CD4 [29]. Several mutant genes were mapped to specific chromosome or chromosome arms. The cn-A1, cn-B1 and cn-D1 from common wheat (Triticum aestivum L.) and durum wheat (T. turgidum L.) were mapped on the long arm of chromosome 7A, 7B and 7D using Chinese Spring (CS) deletion lines, respectively [30]. The similar locus $\mathrm{clm} 1$ in $\mathrm{T}$. monococcum L. was mapped on chromosome $7 \mathrm{~A}^{\mathrm{m}} \mathrm{L}$ [31]. Two loci ygld1 and ygld2 from T. durum var. were mapped on 5AL and 5BL, respectively [32]. The locus Y1718 from cultivar Xinong1718 (T. aestivum L.) was mapped on 2BS [33], yglw-1 was also mapped on $2 \mathrm{~B}$ using a population derived from the cross between Bainong58409/Caifumai [34]. However, none of wheat leaf color mutant genes has been cloned.

Among the regenerated progenies from tissue cultured Yangmai158 using the young embryo as explant, we identified a stable mutant with a phenotype of yellowing leaf color, fewer tiller and dwarfness. The mutant line was given a genetic stock number of NAU31, and the mutant gene was named Tatyd. Interestingly, the mutant showed improved powdery mildew resistance compared with wildtype Yangmai158. This provide an ideal material for investigating the relationship of plant development and disease resistance. In the present study, we characterized the photosynthesis characters and inheritance 
of the mutant traits in NAU31. The gene Tatyd was genetically mapped using an integrated BSA and linkage analysis approach.

\section{Results}

Characterization of a mutant with yellowish leaf, reduced-tillering and dwarfed plant

A yellowing mutant was identified from the regenerated population of Yangmai158, besides the mutant has reduced tillers, dwarfed plant and improved powdery mildew $(\mathrm{Pm})$ resistance. After two generations self-fertilization, these mutant traits could be stably inherited (Fig. 1a). The mutant was named as NAU31. At harvest, the plant heights of Yangmai158 and NAU31 were $84.60 \mathrm{~cm}$ and $49.00 \mathrm{~cm}$, respectively (Fig. 1b), their plant height difference exists throughout the growing period. The tiller numbers of Yangmai158 and NAU31 were 5.40 and 1.67, respectively (Fig. 1c). They both have five internodes on the culm. However, each internode in NAU31 was shortened, with the fifth internode length having the maximum reduction (46.01\% of Yangmai158) (Fig. 1b). Meanwhile, NAU31 showed enhanced powdery mildew resistance compared with Yangmai158 (Fig. 1d). FISH karyotypes of NAU31 and Yangmai158 were compared, and no obvious chromosome changes between the two materials (Additional file 1: Fig. S1).This revealed NAU31 did not undergo significant chromosomal structural variation.

Inheritance Of The Mutated Traits In Nau31

The (NAU31 $\times$ Yangmai 158) $F_{1}$ exhibited plant yellowing phenotype and powdery mildew resistance. Segregation for leaf color in $\mathrm{F}_{2}$ population was observed, the plants could be classified into two types, yellowing type similar to NAU31 and normal green type similar to Yangmai158. Among the $650 \mathrm{~F}_{2}$ individuals, 489 were yellowing type and 161 were normal green, and the segregation ratio fits 3:1 $\left(\chi^{2}=\right.$ $\left.0.018 \otimes \chi_{0.05,1}^{2}=3.84\right)$. Moreover, all yellowing plants were powdery mildew resistant and those green were susceptible. These results showed that the yellowing phenotype was controlled by a dominant gene, and the yellowing trait was closely correlated with powdery mildew resistance.

The $F_{2}$ population were investigated for plant height, spike length, total and effective tiller number. The plant height and spike length showed normal distribution, while the total and effective tiller number showed bimodal distribution (Additional file 1: Fig. S2). Genetic correlations analysis showed that leaf color was significantly and positively correlated with plant height, total and effective tiller number (Table 1). We presume that the mutated locus in NAU31 has pleiotropic effects on plant morphology and Pm resistance.

Linkage Analysis Of The Yellowing Trait In Nau31

The $F_{2}$ population of 'NAU31 $\times$ W7984' was developed. Out of $1390 F_{2}$ individuals, 1013 were yellowing and 377 were normal green, fitting a segregation ratio of $3: 1\left(\chi^{2}=3.34 \otimes \chi^{2}{ }_{0.05,1}=3.84\right)$. This confirmed 
the mutated trait was controlled by a single dominant locus, which has pleiotropic effects. In this study, we only used plant yellowing for further genetic mapping of the muatnt traits.

A total of 1280 SSR markers evenly distributed in wheat genome were selected for polymorphism screening between NAU31 and W7984. Among them, 124 markers were pleiotropic and used for BSA using the "yellow" and "green" bulks (Y-Bulk-1 and G-bulk-1, see method). Five markers (WMC111, Cfd51, gwm296, wmc503 and WMC112) were polymorphic, and they all located on chromosome arm 2DS (Fig. 2a, Additional file 3). The Tatyd gene was preliminary located on 2DS. Linkage analysis was performed using the above five polymorphism SSR markers in $183\left(\right.$ NAU31 $\times$ W7984) $F_{2}$ individuals. Four co-dominant markers (Cfd51, WMC111, wmc503 and WMC 112) fit the segregation ratio of 1:2:1, and one dominant marker gwm296 fit the segregation ratio of 3:1. A linkage map was constructed, and Tatyd was mapped between SSR markers WMC111 and gwm296 with a genetic distance of $1.3 \mathrm{cM}$ and $0.6 \mathrm{cM}$, respectively (Fig. 2b). Our genetic map had same marker order as the previously 2D SSR map reported by Somers et al. (2004) [35](Fig. 2b).

BSA was further performed by the wheat $55 \mathrm{k}$ SNP array using the two DNA bulks (Y-Bulk-2 and G-bulk-2) together with the two parents. A total of 374 polymorphic SNPs were identified between the two parents as well as between the two bulks. Among these SNPS, 146 were located on chromosome 2D. Most of these SNPs located within the interval of 6-24 Mb genome region of 2DS, where the Tatyd were located by SSR marker analysis (Fig. 2c).

Fine mapping of Tatyd

To fine mapping Tatyd, two flanking markers WMC111 and gwm296 were used to genotype 1390 'NAU31 $\times$ W7984' $F_{2}$ plants and 442 derived $F_{2: 3}$ plants. Seventeen recombinants were identified. To enrich the marker density of the Tatyd region flanked by WMC111 and gwm296, we developed ten new markers ( 5 SNP and 5 SSR) (Additional file 1: Fig. S3, Additional file 2: Table S1, Additional file 4). All were polymorphic and used to genotype the 17 recombinants. By this, we divided them into seven haplotypes, three were yellowing type and four were normal green type. Thus, Tatyd was finely mapped to 2DS flanked by ZH47 and gwm296, representing a physical interval of 0.76 Mb (Fig. 2d).

Leaf yellowing is associated with the photosynthesis ability in NAU31

To help the candidate gene prediction and the cause of mutant morphology, we compared the photosynthesis ability and transcriptional profiling between the Yangmai158 and NAU31. The Fv/Fm and Net photosynthetic rate were compared in flag leaf. The flag leaf Fv/Fm of NAU31 significantly lower (0.7940) than Yangmai158 (0.8153) at adult stage (Fig. 3b, 3d), and most of their growth periods (Fig. 3f). The Net photosynthetic rate of NAU31 $\left(2.51 \mu \mathrm{mol} / \mathrm{m}^{2} \cdot \mathrm{s}\right)$ was also significantly lower than Yangmai158 $\left(11.50 \mu \mathrm{mol} / \mathrm{m}^{2} \cdot \mathrm{s}\right)$ (Fig. 3e). This indicated that yellowing leaves of NAU31 had reduced photosynthetic capacity. The photosynthetic pigment contents and SPAD value at the adult stage were measured. The results showed that $\mathrm{Chl} \mathrm{a,} \mathrm{Chl} \mathrm{b,} \mathrm{total} \mathrm{flag} \mathrm{leaf} \mathrm{chlorophyll} \mathrm{and} \mathrm{carotenoid} \mathrm{contents} \mathrm{in}$ NAU31 were $0.46 \mathrm{mg} / \mathrm{g}, 0.11 \mathrm{mg} / \mathrm{g}, 0.57 \mathrm{mg} / \mathrm{g}$ and $0.09 \mathrm{mg} / \mathrm{g}$, which decreased by $84 \%, 89 \%, 86 \%$ and 
81\%, respectively,compared with those in Yangmai158 (Fig. 3g). The SPAD value decreased from 45.21 in Yangmai158 to 25.05 in NAU31 (Fig. 3h). The Chl-index of NAU31 was also lower than that of Yangmai158, with the difference became more and more apparent from seedling to adult stage (Fig. 3c, 3i).

To investigate whether the compromised photosynthesis ability in NAU31 was attributed to chloroplast development impairing or structural changes, chloroplast ultrastructure of Yangmai158 and the NAU31 at 2-week growth stage were compared using TEM. Yangmai158 had oval shape mesophyll cells (Fig. 4a), while NAU31 had irregular shape (Fig. 4b). Yangmai158 and NAU31 had no significant difference in the chloroplast size or number. However, chloroplasts in the mesophyll cells of Yangmai158 had well-defined grana and regularly shaped starch grains; in contrast, chloroplasts in NAU31 showed abnormal shape, had vague thylakoid boundaries, and compromised normal oval shape starch grains (Fig. 4c, 4d).

Moreover, the Yangmai158 displayed well-developed lamellar structures, were equipped with normally stacked grana, thylakoid membranes and regularly shaped plastoglobuli. The thylakoid lamellar structures in the chloroplasts of NAU31 were looser and its plastoglobuli were irregular (Fig. 4e, 4f). We proposed yellowing trait of NAU31 may attributed to reduced photosynthesis ability due to changes of the chloroplast inner structure.

The differentially expressed genes (DEGs) between NAU31 and Yangmai158 at two development stages were compared using RNA-seq of NAU31 and Yangmai158 leaves at two-and four-leaf stages. At the twoleaf stage, RNA-seq identified 17,480 DEGs in NAU31, including 15,042 up-regulated and 2,438 downregulated genes. At the four-leaf stage, RNA-seq identified 19,156 DEGs in NAU31, including 14,286 upregulated and 4,870 down-regulated genes. The KEGG enrichment of DEGs showed that at the two stages, photosynthesis - antenna proteins (ID: ko 00196) pathway could be enriched, with 68 DEGs being commonly present at the two stages, and most were down-regulated. At two-leaf stage, 65 and 3 DEGs were down- and up-regulated, respectively; at four-leaf stage, 66 and 2 DEGs were down- and upregulated, respectively (Fig. 5a). Twelve DEGs related to the photosynthesis - antenna proteins pathway were selected for to qRT-PCR. The expression levels of all tested DEGs were significantly lower in NAU31 than those in Yangmai158 at both growth stages (Fig. 5b), further confirming the down-regulation of the photosynthesis pathway in NAU31. These results showed that compromise of photosynthesis may cause the plant yellowing trait in NAU31.

\section{Discussion}

The mutant traits in NAU31 is controlled by a dominant locus

Leaf color mutants are ideal materials for the study of photosynthesis, chloroplast development and Chlorophyll biosynthesis [20]. Various leaf color mutants have been identified in crops such as maize and rice $[19,20]$. The type of leaf color mutants were classified into eight classes: white; yellow; light green; upper portion white, lower portion green; upper portion green, lower portion white; upper portion yellow, lower portion green; upper portion green, lower portion yellow and chlorophyll deficiency in stripes [36]. The NAU31 is yellow leaf mutant. Various agronomic traits have been reported to be related to the 
photosynthetic machinery in rice, maize and wheat $[33,34,37,38]$. The chlorina mutant plants directly reduces the accumulation of photosynthetic products and also affects yield and grain quality significantly and negatively. The plant height, tiller number and grain yield were significantly reduced in the OsPS1-F mutant (Photosystem 1-F subunit was mutated by Ds insertion) [8]. In wheat, the agronomic traits spike length, number of kernels per spike and 1000-kernel weight of the yglw-1 mutant were significantly decreased, compared to the wild type [34]. In present study, plant height, tiller number, spike length, effective tiller number, spikelet size, seed size and 1000-grain weight were significantly lower in NAU31 mutant than that of wildtype Yangmai158. Therefore, similar to the previous reports for the productivity and yield influenced in leaf color mutants, this yellowing NAU31 mutant also negatively impact agronomic traits.

In wheat, leaf color mutations have also been reported and were associated with different genetic regions $[30,31,39,40]$. In common wheat, the leaf color trait of Ygm mutant was controlled by a incompletely dominant gene, named Y1718, the Y1718 was mapped between SSR marker Xwmc25 and EST-STS marker BE498358, with genetic distances of 1.7 and $4.0 \mathrm{cM}$, respectively [33]. The leaf color trait of yglw1 mutant was controlled by a recessive gene, the yglw-1 gene was mapped between SSR markers Xhwm1 and Xhwm43, with genetic distances of 1.9 and $23.9 \mathrm{cM}$, respectively [34]. In the present study, we identified a yellow leaf mutant, the leaf color trait of NAU31 was controlled by a dominant gene, named Tatyd, the Tatyd was mapped to 2DS between SSR markers ZH47 (16,845,340 bp) and gwm296 $(17,609,164 \mathrm{bp})$. As mentioned above, $\mathrm{Y} 1718$ and yglw-1 were mapped to $2 \mathrm{~B}$. The yglw-1 is mapped within Xhwm1 and Xhwm43, which corresponds to 109,121,927 to 111,574,556 bp region on chromosome 2D of Chinese Spring reference sequence. The Y1718 is mapped within BE498358 and CJ945085, which corresponds to $8,567,431$ to $15,604,263$ bp region on chromosome $2 \mathrm{D}$. Therefore, they are not homoeologous alleles because they were not mapped to the same synteny regions among subgenomes. These results indicate that Tatyd is a new gene related to leaf color.

The NAU31 is likely associated with impairing in photosynthetic pigment pathway

The impairing in photosynthetic metabolism or photosynthetic pigments and Chlorophyll development could lead to the mutation in leaf color in crop. More than 50 leaf color genes have been cloned [19], among them, some genes directly participated in metabolism of photosynthetic pigments, for example OsCHLH [41] and YGL1 [42]; and some genes indirectly influenced metabolism of photosynthetic pigments through other biological pathways, for example OsObgc [43] and FdC2 [44], the content and distribution of photosynthetic pigment determined the color of leaf and the capacity of photosynthesis $[38,45]$. Chlorophyll fluorescence is a useful technique for studying the mechanism of photosynthesis, photosynthetic capacity and heritable variants of plants [46, 47]. The changes in leaf color generally lead to changes in photosynthesis capacity and photosynthetic pigment of plant. In maize, the contents of total $\mathrm{Chl} \mathrm{s,} \mathrm{Chl} \mathrm{a,} \mathrm{Chl} \mathrm{b} \mathrm{and} \mathrm{Car} \mathrm{of} \mathrm{ygl-1} \mathrm{mutant} \mathrm{were} \mathrm{significantly} \mathrm{reduced} \mathrm{of} 24.32 \%, 20.4 \%, 40.2 \%$, and $1.96 \%$, respectively, which lowered the capacity of photosynthesis compared with the wild type Lx7226 [20]. In Lotus japonicas, the content of chlorophylls and the ratio of Fv/Fm of C16 mutant showed lower than that of wild type, indicating that the photosynthesis capacity of C16 is lower than that of wild type 
[48]. In rice, the content of photosynthetic pigment is lower in ygl7 than that in the wild type, but the photoelectron utilization rate, photosynthetic rate, the net photosynthesis and dark respiration rates of ygl7 were higher than WT, maybe caused by genes associated with photosynthesis were mostly upregulated in ygl7 [22]. In wheat, the pigment of Ygm mutant were reduced compared with wild type Xinong1718, but the $\mathrm{Chl} \mathrm{a/b}$ ratio in Ygm leaves were 3.81-5.64 times higher compared Xinong1718 [33]. In present study, the photosynthetic pigment ( $\mathrm{Chl} \mathrm{a}, \mathrm{Chl} b, \mathrm{Chl} \mathrm{a}+\mathrm{b}$ and $\mathrm{Car}$ ) and net photosynthetic rate of NAU31 mutant were lower than that of wild type Yangmai158 in flowering stage. Fv/Fm of NAU31 was significantly lower than that of Yangmai158 in most of the growth period. Transcriptome analysis results showed that many DEGs associated with photosynthesis were mostly down-regulated in NAU31, indicating that the lower photosynthetic capacity may be caused by lower content of chlorophylls in NAU31, which is similar to the relationship between photosynthetic pigment content and photosynthetic capacity in papaya plants[49].

The Leaf color mutation increase resistance to powdery mildew of NAU31

Changes in photosynthesis capacity directly affect plant disease resistance $[9,50]$. In recent years, many studies have found that chloroplasts participate in interaction between plants and pathogens through salicylic acid (SA), jasmonic acid (JA), and reactive oxygen species (ROS) pathway [51]. In Arabidopsis, MPK3/MPK6 can inhibit photosynthesis by down-regulated the expression of photosynthesis-related genes and then increase effector-triggered Immunity (ETI) [11]. In wheat, WKS1 interacts with phosphorylates PsbO, and leading a fast degradation of PsbO, to reduce photosynthesis and regulate leaf chlorosis in conferring Pst resistance [52]. In this study, NAU31 was yellowing and its photosynthesis capacity was reduced, and many photosynthesis - antenna proteins pathway relate genes were significantly down-regulated compared with Yangmai158. Indicating that the resistance of NAU31 to powdery mildew may be increased through reduced photosynthesis.

\section{Conclusions}

This study identified a new wheat few-tiller, plant yellowish, dwarfness and improved powdery mildew resistance mutant, named NAU31. Inheritance analysis of NAU31 showed that the above mutant traits were significantly correlated and controlled by a dominant gene, named Tatyd. Tatyd was fine mapped to a $0.76 \mathrm{Mb}$ genome region of wheat chromosome 2D. The photosynthetic capacity of NAU31 was significantly reduced compared to the wild type Yangmai158, which may lead to increased resistance to powdery mildew.

\section{Methods}

Plant materials

Commercial wheat variety Yangmai158 was cultivated in Institute of Agricultural Sciences in Lixiahe District of Jiangsu Province, Sumai3 was cultivated in Suzhou Academy of Agricultural Sciences, Chinese 
Spring (CS) is a Chinese wheat landrace. All materials were maintained at the Cytogenetics Institute, Nanjing Agricultural University (CINAU). Yangmai158 is susceptible to wheat powdery mildew. NAU31 is a mutant, which was identified from the regenerated plants of a tissue cultured population of Yangmai158. The protocol of wheat tissue culture followed Xing et al. (2008). [53]. The mutant was self-fertilized for two generations, and its mutant phenotype (few-tiller, dwarfness, yellow leaf and powdery mildew resistance) could be stably inherited (Fig. 1a). Synthetic W7984 is a contemporary reconstitution of hexaploid wheat were kindly provided by Dr. M. E. Sorrells of Cornell University, USA. Three "Chinese Spring" (CS) nulli-tetrasomic lines (N2AT2D, N2BT2A and N2DT2A) were kindly provided by Dr. BS Gill of Kansas State University, Kansas, USA. Triticum durum ( $\mathrm{Cl} 1286)$ was introduced from Chinese Academy of Agriculture Sciences (CAAS). Aegilops tauschii (accession no: AL8/78) were introduced from U. S. National Plant Germplasm System, USA. The above materials were used for markers analysis. Highly powdery mildew susceptible wheat variety, Sumai 3, was used for the production of fresh Bgt inoculums.

The (NAU31 $\times$ Yangmai158) $F_{1}$ and $F_{2}$ population consisted of 650 individuals were used for genetic analysis. The $(\mathrm{NAU} 31 \times$ W7984 $) \mathrm{F}_{2}$ individuals and their derived $\mathrm{F}_{2: 3}$ lines were used for molecular mapping based on marker analysis. All materials were grown in the experimental station of Zhenjiang Institute of Agricultural Sciences, Zhenjiang, Jiangsu, China.

Evaluation Of Powdery Mildew Resistance

The single Bgt isolate E26 provided by Prof. Yilin Zhou from Chinese Academy of Agriculture Sciences (CAAS) and mixed Bgt isolates (collected from Nanjing, China) were maintained on two-leaf stage seedlings and fresh spores were used as inoculum to test the Pm resistance. For plants grown in an incubator, the 4th leaves of plants at the 5th leaf growth stage were cut to test the Pm resistance by artificial Bgt inoculation. The plants grown in the field were used for adult stage Pm resistance evaluation by artificial inoculation with mixed Bgt isolates. The resistance level was classified as grades $0-4$ as described by Sheng (1988)[54], in which grades " $0-2$ " were regarded as resistant, and grades " $3-4$ " were moderately and highly susceptible, respectively.

Investigation Of Agronomic Traits

NAU31, Yangmai158, W7984, and their derived $F_{1}, F_{2}, F_{2: 3}$ (derived from $F_{2}$ of 'NAU31 $\times$ W7984') were grown in $1.5 \mathrm{~m}$ rows, with row space being $25 \mathrm{~cm}$. Thirty seeds were grown in each row. The field management followed local agronomic practices. The plant leaf color was measured in the field trials at both seeding and adult stages. At maturity stage, nine agronomic traits of NAU31 and Yangmai158, i.e. plant height, internode length, spike length, total tiller number per plant, effective tiller number per plant, spikelet number per spike, 1000-grain weight, grain length and grain width, were investigated. A total of 30 plants from the middle rows of each trial were investigated and their average data were used for statistical analysis by t-tests using SPSS 16.0 software [55].

Transmission Electron Microscopy (tem) 
TEM analysis was carried out as described previously [56] with minor modifications. The leaves of Yangmai158 and NAU31 were harvested in 2-week-old seedlings stage,fixed in 2.5\% glutaraldehyde in $0.1 \mathrm{mM}$ phosphate buffer ( $\mathrm{pH} 7.2)$ at $4{ }^{\circ} \mathrm{C}$ for $24 \mathrm{~h}$. After washed with $0.1 \mathrm{M}$ phosphate buffer $(\mathrm{pH} 7.2)$, the leaves were post-fixed with $1 \%$ osmium tetroxide. The samples were embedded in Spurr resin, and 0.5$\mu \mathrm{m}$ sections were cut with a UC7 Ultramicrotome (Leica, Germany). The sections were observed and the pictures were captured using an H-7650 transmission electron microscope (Hitachi Science Systems Ltd, Japan).

\section{Measurement Of Photosynthetic Pigment Contents}

Two methods were used to determine the photosynthetic pigment contents. (1) The flag leaf chlorophyll content was measured using a chlorophyll meter SPAD-502 (Konica minolta, Inc., Japan), three points were measured on each flag leaf of Yangmai158 and NAU31, and then averaged, respectively. Each sample had 10 replicates. (2) The fresh samples of the flag leaf at heading stage were collected from NAU31 and Yangmai158 in the field. For each sample, $0.1 \mathrm{~g}$ was cut into small pieces and immersed in $25 \mathrm{~mL}$ extraction solution containing acetone and absolute ethanol $(1: 1, \mathrm{v} / \mathrm{v})$. The samples were mixed well, incubated in the dark at $25^{\circ} \mathrm{C}$ for $24 \mathrm{~h}$, and measured at $663 \mathrm{~nm}, 645 \mathrm{~nm}$ and $470 \mathrm{~nm}$ by using a T-6 spectrophotometer (Philes, China). The concentration $\left(\mathrm{mg} \mathrm{L}^{-1}\right)$ was calculated using the following formulas:

Concentration of chlorophyll "a": $\mathrm{C}_{\mathrm{Chl}} \mathrm{a}=12.72 \times \mathrm{A} 663-2.59 \times \mathrm{A} 645$;

Concentration of chlorophyll "b": $\mathrm{C}_{\mathrm{Chl}} \mathrm{b}=22.88 \times \mathrm{A} 645-4.67 \times \mathrm{A} 663$;

Concentration of carotenoid: $\mathrm{C}_{\mathrm{car}}=(1000 \mathrm{~A} 470-3.27 \mathrm{Ca}-104 \mathrm{Cb}) / 229$.

The photosynthetic pigment content $\left(\mathrm{mg} \mathrm{g}^{-1}\right)$ was calculated using the formula:

$m_{x}=C \times V \times N / W \times 1000$, in which $m$ is photosynthetic pigment content, $C$ is photosynthetic pigment concentration, $\mathrm{V}$ is volume of extraction solution, $\mathrm{W}$ is fresh sample weight and $\mathrm{N}$ is the dilution factor.

Measurement Of Chlorophyll Fluorescence And Photosynthetic Parameter

The maximum quantum yield of PSII (Fv/Fm) of NAU31 and Yangmai158 were measured after 10 min of dark acclimation by an in vivo chlorophyll "a" fluorometer (Mini-PAM, Germany) at heading stage. The net photosynthetic rate of the flag leaves at grain filling stage ( 25 days after flowering) was measured in the field, using the Li-6400 portable photosynthesis system (LI-Cor, Inc.) at midday, when the light intensity is about $1300 \mu \mathrm{mol} \mathrm{m} \mathrm{m}^{-2} \mathrm{~s}^{-1}$ and $\mathrm{CO}_{2}=400 \mu \mathrm{mol} \mathrm{mol}^{-1}$. Ten individuals of NAU31 and Yangmai158 were measured and then averaged, respectively.

To investigate the difference of photosynthesis and plant growth parameters between NAU31 and Yangmai158 during their whole growth period. The seeds of NAU31 and Yangmai158 were sown on wet filter paper and incubated at $4{ }^{\circ} \mathrm{C}$ for $12-14$ days. Three seeds of the same genotype were germinated 
and planted in pots. The growth conditions were as follows: $14 / 10 \mathrm{~h}$ day/night, $24 / 20^{\circ} \mathrm{C}$ day/night temperature and $70 \%$ relative humidity. The plant heights were recorded every day. The photosynthesis parameters (Fv/Fm, Chl-index), chlorophyll fluorescence image and normal image were detected every day at 10 am by PhenoMate (PhenoTrait, Netherlands) during the whole growth period.

\section{Marker Development}

Simple sequence repeat (SSR) and single nucleotide polymorphism (SNP) markers were developed according to the Chinese Spring reference sequence (https://www.wheatgenome.org/). SSR loci were detected using SSR Hunter software, and primer pairs were designed using the online software Primer3 V0.4.0. The 55K wheat SNP array (Affymetrix ${ }^{\circledR}$ Axiom ${ }^{\circledR}$ Wheat55) was used to genotype the NAU31 and W7984. Based on the SNPs detected by SNP array, tetra-SNP primers (Each set contains two forward primers and two reverser primers) were designed by using the online software Primer3 V0.4.0. All the above primer pairs (Additional file 2: Table S1) were synthesized by Tsingke Biological Technology Company.

\section{Bulk Segregant Analysis (bsa)}

The genomic DNA were extracted from young leaves using CTAB method [57]. (1) For BSA using SSR markers, the procedure was performed as described by Qin et al (2015) [21] with the following modifications. Equal amounts of DNA from 10 yellow and 10 normal green individuals from the (NAU31 $\times$ W7984) $F_{2}$ population were pooled and named as Y-bulk-1 and G-bulk-1, respectively. The SSR markers from public databases distributing on the 21 chromosomes of wheat were screened in the parents and the two bulks. PCR reaction and the polyacrylamide gel analysis were conducted to analyze the genotype of the samples according to Xu et al. (2017) [58]. (2) For BSA using 55K SNP assay, equal amounts of DNA from 7 yellow and 7 normal green individuals from (NAU31 $\times$ W7984) $F_{2: 3}$ lines (derived from the above $F_{2}$ ) were pooled and named as $\mathrm{Y}$-bulk-2 and G-bulk-2, respectively. The SNP array was implemented by CapitalBio Corporation (Beijing). Polymorphic SNPs detected from contrasting pools and corresponding parents were assumed to be linked to Tatyd, and they were localized to chromosomes based on data provided by CapitalBio Corporation.

\section{Linkage Map Construction}

The linkage map was constructed using JoinMap 4.0 software at a LOD threshold of 3.0. Linkage groups were assigned to chromosomes by referring to the published genetic maps of wheat (http://wheat.pw.usda.gov/GG2/index.shtml).

\section{Transcriptome Analysis}

The NAU31 and Yangmai158 were grown in pots. Their fresh leaves were collected at the two-leaf stage (NAU31: a-1, a-2, a-3; Yangmai158: b-1, b-2, b-3) and four-leaf stage (NAU31: a-4, a-5, a-6; Yangmai158: b$4, b-5, b-6)$, respectively. Each genotype in each stage has three biological replicates. All of the samples 
were immediately frozen in liquid nitrogen and were stored at $-80^{\circ} \mathrm{C}$. Total RNA was extracted using the Trizol reagent (Invitrogen, USA), according to the manufacturer's instructions. RNA concentration was determined using a NanoDrop spectrophotometer and 1.2\% agarose gel electrophoresis. RNA-Seq was performed using a BGISEQ-500 sequencing platform by BGI Company, Shenzhen, China. The raw reads were cleaned by removing adapter and low-quality sequences (percentage of low-quality bases with a quality value $\leq 10$ in more than $20 \%$ of a read). Mapping of 12 sample clean reads to wheat genome (https://wheat-urgi.versailles.inra.fr/Seq-Repository/Assemblies) was conducted with HISAT2 (v 2.1.0). The new transcripts were assembled with StringTie (v1.0.4). The gene expression levels were calculated by RSEM (v1.2.8, default). The DEGs were detected by DEGseq (Fold Change $>=2$ and Adjusted Pvalue < $=0.001)$. KEGG pathway enrichment analysis of DEGs were performed using the KOBAS software. Zscore normalized log2 FPKM value of the photosynthesis-antenna proteins pathway DEGs were used to generate the heatmap.

Qrt-pcr Analysis

qRT-PCR was to validate the RNA-seq data using the same RNA samples used for RNA-sEq. Chlorophyllrelated DGEs were selected and specific primers were designed using Primer 3. The tubulin gene was used as the internal control for normalization (All primers were shown in Additional file 2: Table S1). qRTPCR was performed with AceQ SYBR Green (Vazyme) using a Louts PCR 480 sequence detection system. The reactions were subjected to the following program: $95^{\circ} \mathrm{C}$ for $1 \mathrm{~min}, 41$ cycles of $95^{\circ} \mathrm{C}$ for $10 \mathrm{~s}$, and $60{ }^{\circ} \mathrm{C}$ for $30 \mathrm{~s}$. The relative value of gene expression were derived from $2^{-\triangle \Delta C T}$ [59]. Three independent biological replications were performed for each sample.

Fluorescence in situ hybridization (FISH)

The slide preparation of NAU31 and Yangmai158 followed Danilova et al. (2012) [60]. Oligonucleotide multiplex FISH was performed as described by Huang et al. 2018 [61] with modifications. The eight single-strand oligonucleotides [including TAMRA (6-carboxytetramethylrhodamine)-modified oligonucleotides of pAs1-1, pAs1-3, pAs1-4, pAs1-6, AFA-3 and AFA-4; FAM (6-carboxyfluorescein)modified oligonucleotides of pSc119.2-1 and (GAA) ${ }_{10}$ ] were used as probes for FISH. The chromosomes were counterstained with 4', 6-diamidino-2-phenylindole (DAPI), the signals were visualized under a fluorescence microscope (Olympus BX60), and images were captured by Spot32 CCD camera [62].

\section{Abbreviations}

BSA Bulk segregant analysis

Car Carotenoid

Chl Chlorophyll

Chl a Chlorophyll "a" 
Chl b Chlorophyll "b"

Chl $a+b$ Chlorophyll "a" and Chlorophyll "b"

Chl-Index Chlorophyll-Index

Fv/Fm Maximum quantum efficiency

PSII Photosystem II

SNP Single nucleotide polymorphism

\section{Declarations}

\section{Ethics approval and consent to participate:}

Not applicable

\section{Consent for publication:}

Not applicable

\section{Availability of data and materials:}

All data generated in this study are included in the paper and in the supporting information files.

\section{Competing interests:}

The authors declare that they have no competing interests

\section{Funding:}

This research was supported by the grants from the National Natural Science Foundation of China (Major Program) (No. 91935304), the International Cooperation and Exchange of the National Natural Science Foundation of China (No. 31661143005), the National Natural Science Foundation of China (No.31971943), the '948' Project of Ministry of Agriculture (2015-Z41), the special fund of Jiangsu Province for the transformation of scientific and technological achievements (BA2017138), the Program of Introducing Talents of Discipline to Universities (B08025), the Creation of Major New Agricultural Varieties in Jiangsu Province (PZCZ201706), the Jiangsu Agricultural Technology System (JATS) (No. JATS [2019] 429), the Key Research and Development Major Project of Ningxia Autonomous Region (No. 2019BBF02022-04). The role of the funding body is to provide financial support. The funders had no role in study design, data collection and analysis, decision to publish, or preparation of the manuscript.

\section{Authors' contributions:}


WXE, XJ and ZH designed experimental plan. ZH, CYM, NY and ZX performed experiments. SL, NY and CYM managed the materials in the field. XJ, ZH and ZX analyzed the data. WXE, WHY, XJ and ZH wrote the manuscript. All authors have read and approved the final manuscript.

\section{Acknowledgements:}

Not applicable

\section{References}

1. Flood PJ, Kruijer W, Schnabel SK, van der Schoor R, Jalink H, Snel JFH, Harbinson J, Aarts MGM: Phenomics for photosynthesis, growth and reflectance in Arabidopsis thaliana reveals circadian and long-term fluctuations in heritability. Plant Methods 2016, 12.

2. Makino A: Photosynthesis, grain yield, and nitrogen utilization in rice and wheat. Plant Physio/2011, 155(1):125-129.

3. Nasyrov YS: Genetic Control of Photosynthesis and Improving of Crop Productivity. Annual Review of Plant Physiology 1978, 29(1):215-237.

4. Kruger EL, Volin JC: Reexamining the empirical relation between plant growth and leaf photosynthesis. Funct Plant Biol 2006, 33(5):421-429.

5. Fischer RA, Rees D, Sayre KD, Lu ZM, Condon AG, Saavedra AL: Wheat yield progress associated with higher stomatal conductance and photosynthetic rate, and cooler canopies. Crop Sci 1998, 38(6):1467-1475.

6. Driever SM, Simkin AJ, Alotaibi S, Fisk SJ, Madgwick PJ, Sparks CA, Jones HD, Lawson T, Parry MAJ, Raines CA: Increased SBPase activity improves photosynthesis and grain yield in wheat grown in greenhouse conditions. Philos T R Soc B 2017, 372(1730).

7. Kromdijk J, Glowacka K, Leonelli L, Gabilly ST, Iwai M, Niyogi KK, Long SP: Improving photosynthesis and crop productivity by accelerating recovery from photoprotection. Science 2016, 354(6314):857861.

8. Ramamoorthy R, Vishal B, Ramachandran S, Kumar PP: The OsPS1-F gene regulates growth and development in rice by modulating photosynthetic electron transport rate. Plant Cell Rep 2018, 37(2):377-385.

9. Zabala MDT, Littlejohn G, Jayaraman S, Studholme D, Bailey T, Lawson T, Tillich M, Licht D, Bolter B, Delfino L, Truman W, Mansfield J, Smirnoff N, Grant M: Chloroplasts play a central role in plant defence and are targeted by pathogen effectors. Nat Plants 2015, 1(6).

10. Xu Q, Tang C, Wang X, Sun S, Zhao J, Kang Z, Wang X: An effector protein of the wheat stripe rust fungus targets chloroplasts and suppresses chloroplast function. Nat Commun 2019, 10(1):5571.

11. Su JB, Yang LY, Zhu QK, Wu HJ, He Y, Liu YD, Xu J, Jiang DA, Zhang SQ: Active photosynthetic inhibition mediated by MPK3/MPK6 is critical to effector-triggered immunity. Plos Bio/2018, 16(5). 
12. Yang DL, Li S, Li MF, Yang XL, Wang WT, Cao ZY, Li W: Physiological Characteristics and Leaf Ultrastructure of a Novel Chlorophyll-deficient chd6 Mutant of Vitis venifera Cultured in vitro. J Plant Growth Regul 2012, 31(1):124-135.

13. Zhang HT, Li JJ, Yoo JH, Yoo SC, Cho SH, Koh HJ, Seo HS, Paek NC: Rice chlorina-1 and chlorina-9 encode ChID and Chll subunits of Mg-chelatase, a key enzyme for chlorophyll synthesis and chloroplast development. Plant Mol Biol 2006, 62(3):325-337.

14. Tanaka A, Tanaka R: Chlorophyll metabolism. Curr Opin Plant Bio/2006, 9(3):248-255.

15. Nagata N, Tanaka R, Satoh S, Tanaka A: Identification of a vinyl reductase gene for chlorophyll synthesis in Arabidopsis thaliana and implications for the evolution of Prochlorococcus species. Plant Cell 2005, 17(1):233-240.

16. Douzery EJP, Snell EA, Bapteste E, Delsuc F, Philippe H: The timing of eukaryotic evolution: Does a relaxed molecular clock reconcile proteins and fossils? Proceedings of the National Academy of Sciences of the United States of America 2004, 101(43):15386-15391.

17. Pogson BJ, Albrecht V: Genetic dissection of chloroplast biogenesis and development: an overview. Plant Physiol 2011, 155(4):1545-1551.

18. Peng Y, Zhang Y, Lv J, Zhang J, Li P, Shi X, Wang Y, Zhang H, He Z, Teng S: Characterization and fine mapping of a novel rice albino mutant low temperature albino 1 . Journal of genetics and genomics 2012, 39(8):385-396.

19. Ma XZ, Sun XQ, Li CM, Huan R, Sun CH, Wang Y, Xiao FL, Wang Q, Chen PR, Ma FR, Zhang K, Wang $P R$, Deng XJ: Map-based cloning and characterization of the novel yellow-green leaf gene $y s 83$ in rice (Oryza sativa). Plant Physiol Bioch 2017, 111:1-9.

20. Guan H, Xu X, He C, Liu C, Liu Q, Dong R, Liu T, Wang L: Fine Mapping and Candidate Gene Analysis of the Leaf-Color Gene ygl-1 in Maize. Plos One 2016, 11(4):e0153962.

21. Qin D, Dong J, Xu F, Guo G, Ge S, Xu Q, Xu Y, Li M: Characterization and fine mapping of a novel barley Stage Green-Revertible Albino Gene (HVSGRA) by Bulked Segregant Analysis based on SSR assay and Specific Length Amplified Fragment Sequencing. BMC genomics 2015, 16:838.

22. Deng XJ, Zhang HQ, Wang Y, He F, Liu JL, Xiao X, Shu ZF, Li W, Wang GH, Wang GL: Mapped Clone and Functional Analysis of Leaf-Color Gene Ygl7 in a Rice Hybrid (Oryza sativa L. ssp indica). Plos One 2014, 9(6).

23. Sawers RJ, Linley PJ, Gutierrez-Marcos JF, Delli-Bovi T, Farmer PR, Kohchi T, Terry MJ, Brutnell TP: The Elm1 (ZmHy2) gene of maize encodes a phytochromobilin synthase. Plant Physiol 2004, 136(1):2771-2781.

24. Sawers RJH, Viney J, Farmer PR, Bussey RR, Olsefski G, Anufrikova K, Hunter CN, Brutnell TP: The maize Oil yellow1 (Oy1) gene encodes the I subunit of magnesium chelatase. Plant Mol Biol 2006, 60(1):95-106.

25. Shi D, Zheng X, Li L, Lin W, Xie W, Yang J, Chen S, Jin W: Chlorophyll deficiency in the maize elongated mesocotyl 2 mutant is caused by a defective heme oxygenase and delaying grana stacking. Plos One 2013, 8(11):e80107. 
26. Schultes NP, Sawers RJH, Brutnell TP, Krueger RW: Maize high chlorophyll fluorescent 60 mutation is caused by an Ac disruption of the gene encoding the chloroplast ribosomal small subunit protein 17. Plant J 2000, 21(4):317-327.

27. Xing A, Williams ME, Bourett TM, Hu W, Hou Z, Meeley RB, Jaqueth J, Dam T, Li B: A pair of homoeolog ClpP5 genes underlies a virescent yellow-like mutant and its modifier in maize. Plant $J$ 2014, 79(2):192-205.

28. Neatby KW: A chlorophyll mutation in wheat. J Hered 1933, 24(4):159-162.

29. Williams ND, Joppa LR, Duysen ME, Freeman TP: Inheritance Of $\mathbf{3}$ Chlorophyll-Deficient Mutants Of Common Wheat. Crop Sci 1985, 25(6):1023-1025.

30. Watanabe N, Koval SE: Mapping of chlorina mutant genes on the long arm of homoeologous group 7 chromosomes in common wheat with partial deletion lines. Euphytica 2003, 129(3):259-265.

31. Ansari MJ, Al-Ghamdi A, Kumar R, Usmani S, Al-Attal Y, Nuru A, Mohamed AA, Singh K, Dhaliwal HS: Characterization and gene mapping of a chlorophyll-deficient mutant clm1 of Triticum monococcum L. Biol Plantarum 2013, 57(3):442-448.

32. Li N, Jia JZ, Xia C, Liu X, Kong XY: Characterization and mapping of novel chlorophyll deficient mutant genes in durum wheat. Breeding Sci 2013, 63(2):169-175.

33. Zhang LL, Liu C, An XY, Wu HY, Feng Y, Wang H, Sun DJ: Identification and genetic mapping of a novel incompletely dominant yellow leaf color gene, $Y 1718$, on chromosome 2BS in wheat. Euphytica 2017, 213(7).

34. Li XJ, Ding WH, Chen XD, Li G, Jiang XL, Dong N, Xiao YJ, Ren CC, Gao XH, Ru ZG: Genetics and mapping of the novel leaf-colour mutant gene yglw-1 on wheat chromosome arm 2BS. Crop Pasture Sci 2018, 69(10):955-965.

35. Somers DJ, Isaac P, Edwards K: A high-density microsatellite consensus map for bread wheat (Triticum aestivum L.). Theoretical and applied genetics 2004, 109(6):1105-1114.

36. Awan MA, Konzak CF, Rutger JN, Nilan RA: Mutagenic Effects of Sodium Azide in Rice. Crop Sci 1980, 20:663-668.

37. Ambavaram MMR, Basu S, Krishnan A, Ramegowda V, Batlang U, Rahman L, Baisakh N, Pereira A: Coordinated regulation of photosynthesis in rice increases yield and tolerance to environmental stress. Nat Commun 2014, 5.

38. Deng LC, Qin P, Liu Z, Wang GL, Chen WL, Tong JH, Xiao LT, Tu B, Sun YT, Yan W, He H, Tan J, Chen XW, Wang YP, Li SG, Ma BT: Characterization and fine-mapping of a novel premature leaf senescence mutant yellow leaf and dwarf 1 in rice. Plant Physiol Bioch 2017, 111:50-58.

39. Klindworth DL, Williams ND, Duysen ME: Genetic-Analysis Of Chlorina Mutants Of Durum-Wheat. Crop Sci 1995, 35(2):431-436.

40. Freeman TP, Duysen ME, Williams ND: Effects Of Gene Dosage on Light Harvesting Chlorophyll Accumulation, Chloroplast Development, And Photosynthesis In Wheat (Triticum-Aestivum). Can J Bot 1987, 65(10):2118-2123. 
41. Jung KH, Hur J, Ryu CH, Choi Y, Chung YY, Miyao A, Hirochika H, An GH: Characterization of a rice chlorophyll-deficient mutant using the T-DNA gene-trap system. Plant Cell Physiol 2003, 44(5):463472.

42. Wu ZM, Zhang X, He B, Diao LP, Sheng SL, Wang JL, Guo XP, Su N, Wang LF, Jiang L, Wang CM, Zhai $\mathrm{HQ}$, Wan JM: A chlorophyll-deficient rice mutant with impaired chlorophyllide esterification in chlorophyll biosynthesis. Plant Physio/ 2007, 145(1):29-40.

43. Bang WY, Chen J, Jeong IS, Kim SW, Kim CW, Jung HS, Lee KH, Kweon HS, Yoko I, Shiina T, Bahk JD: Functional characterization of $\mathrm{ObgC}$ in ribosome biogenesis during chloroplast development. Plant $\mathrm{J}$ 2012, 71(1):122-134.

44. Li CM, Hu Y, Huang R, Ma XZ, Wang Y, Liao TT, Zhong P, Xiao FL, Sun CH, Xu ZJ, Deng XJ, Wang PR: Mutation of $F d C 2$ gene encoding a ferredoxin-like protein with C-terminal extension causes yellowgreen leaf phenotype in rice. Plant Sci 2015, 238:127-134.

45. Mlodzinska E: Survey Of Plant Pigments: Molecular And Environmental Determinants Of Plant Colors. Acta Biol Cracov Bot 2009, 51(1):7-16.

46. Murchie EH, Lawson T: Chlorophyll fluorescence analysis: a guide to good practice and understanding some new applications. Journal of experimental botany 2013, 64(13):3983-3998.

47. Wang J, Li X, Lu D, Du Y, Ma L, Li WJ, Chen JH, Li FL, Fan Y, Hu GR, Wang JF: Photosynthetic Effect in Selenastrum capricornutum Progeny after Carbon-Ion Irradiation. Plos One 2016, 11(2).

48. Cui T, Luo SW, Du Y, Yu LX, Yang JY, Li WJ, Chen X, Li X, Wang J, Zhou LB: Research of photosynthesis and genomewide resequencing on a yellow-leaf Lotus japonicus mutant induced by carbon ion beam irradiation. Grass/ Sci 2019, 65(1):41-48.

49. Paixao JS, Da Silva JR, Ruas KF, Rodrigues WP, Machado JA, Bernado WD, Abreu DP, Ferreira LS, Gonzalez JC, Griffin KL, Ramalho JC, Campostrini E: Photosynthetic capacity, leaf respiration and growth in two papaya (Carica papaya) genotypes with different leaf chlorophyll concentrations. Aob Plants 2019, 11(2).

50. Bilgin DD, Zavala JA, Zhu J, Clough SJ, Ort DR, DeLucia EH: Biotic stress globally downregulates photosynthesis genes. Plant Cell Environ 2010, 33(10):1597-1613.

51. Padmanabhan MS, Dinesh-Kumar SP: All Hands on Deck-The Role of Chloroplasts, Endoplasmic Reticulum, and the Nucleus in Driving Plant Innate Immunity. Mol Plant Microbe In 2010, 23(11):1368-1380.

52. Wang S, Li QP, Wang J, Yan Y, Zhang GL, Yan Y, Zhang H, Wu J, Chen F, Wang X, Kang Z, Dubcovsky J, Gou JY: YR36/WKS1-mediated Phosphorylation of PsbO, an Extrinsic Member of Photosystem II, Inhibits Photosynthesis and Confers Stripe Rust Resistance in Wheat. Molecular plant 2019.

53. Xing LP, Wang HZ, Jiang ZN, Ni JL, Cao AZ, Yu L, Chen PD: Transformation of Wheat Thaumatin-Like Protein Gene and Analysis of Reactions to Powdery Mildew and Fusarium Head Blight in Transgenic Plants. Acta Agronomica Sinica 2008, 34(3):349-354.

54. Sheng B: Grades of resistance to powdery mildew classified by different phenotypes of response in the seeding stage of wheat. Plant Prot 1988, 1. 
55. Norusis M: SPSS 16.0 Guide to Data Analysis. In: Englewood Cliffs; NJ. Prentice Hall Press 2008.

56. Wang Y, Zheng W, Zheng W, Zhu J, Liu Z, Qin J, Li H: Physiological and transcriptomic analyses of a yellow-green mutant with high photosynthetic efficiency in wheat (Triticum aestivum L.). Functional \& integrative genomics 2018, 18(2):175-194.

57. Murray MG, Thompson WF: Rapid isolation of high molecular weight plant DNA. Nucleic acids research 1980, 8(19):4321-4325.

58. Xu T, Bian N, Wen M, Xiao J, Yuan C, Cao A, Zhang S, Wang X, Wang H: Characterization of a common wheat (Triticum aestivum L.) high-tillering dwarf mutant. Theoretical and applied genetics 2017, 130(3):483-494.

59. Livak KJ, Schmittgen TD: Analysis of relative gene expression data using real-time quantitative PCR and the $2^{-\triangle \Delta C T}$ method. Methods 2001, 25(4):402-408.

60. Danilova TV, Friebe B, Gill BS: Single-copy gene fluorescence in situ hybridization and genome analysis: Acc-2 loci mark evolutionary chromosomal rearrangements in wheat. Chromosoma 2012, 121(6):597-611.

61. Huang XY, Zhu MQ, Zhuang LF, Zhang SY, Wang JJ, Chen XJ, Wang DR, Chen JY, Bao YG, Guo J, Zhang JL, Feng YG, Chu CG, Du P, Qi ZJ, Wang HG, Chen PD: Structural chromosome rearrangements and polymorphisms identified in Chinese wheat cultivars by high-resolution multiplex oligonucleotide FISH. Theoretical And Applied Genetics 2018, 131(9):1967-1986.

62. Du P, Zhuang LF, Wang YZ, Yuan L, Wang Q, Wang DR, Dawadondup, Tan LJ, Shen J, Xu HB, Zhao H, Chu CG, Qi ZJ: Development of oligonucleotides and multiplex probes for quick and accurate identification of wheat and Thinopyrum bessarabicum chromosomes. Genome 2017, 60(2):93-103.

\section{Supplementary Files Legend}

Additional file 1: Fig. S1 Oligonucleotide multiplex FISH-based karyotype of Yangmai158 and NAU31. Bar $=20 \mu \mathrm{m}$.

Additional file 1: Fig. S2 Frequency distribution of plant height, spike length, total tiller number and effective tiller number in the F2 population which were derived from crosses of Yangmai158 and NAU31. Plant height (a), Spike length (b), Total tiller number (c) and Effective tiller number (d) of the F2 population derived from crosses of Yangmai158 and NAU31.

Additional file 1: Fig. S3 The specific amplicon of the SSR marker ZH47 was tightly linked to Tatyd. Marker: DL 2000 DNA ladder; CS: Chinese Spring; Td.: T. durum; Aet.: Ae. tauschii; N2AT2D, N2BT2A and N2DT2A are three Nulli-Tetrasomic lines of Chinese Spring; Yangmai158: wild type; NAU31: mutant of Yangmai158; W7984: synthetic hexaploidy wheat. The red arrow indicates the specific bands for each sub-genome.

Additional file 2: Table S1 Primer pairs used in this study 
Additional file 3: The original gel image of figure 2a. The Black boxes indicate the image used in figure 2a.

Additional file 4: The original gel image of figure S3. The Black boxes indicate the image used in figure S3.

\section{Figures}
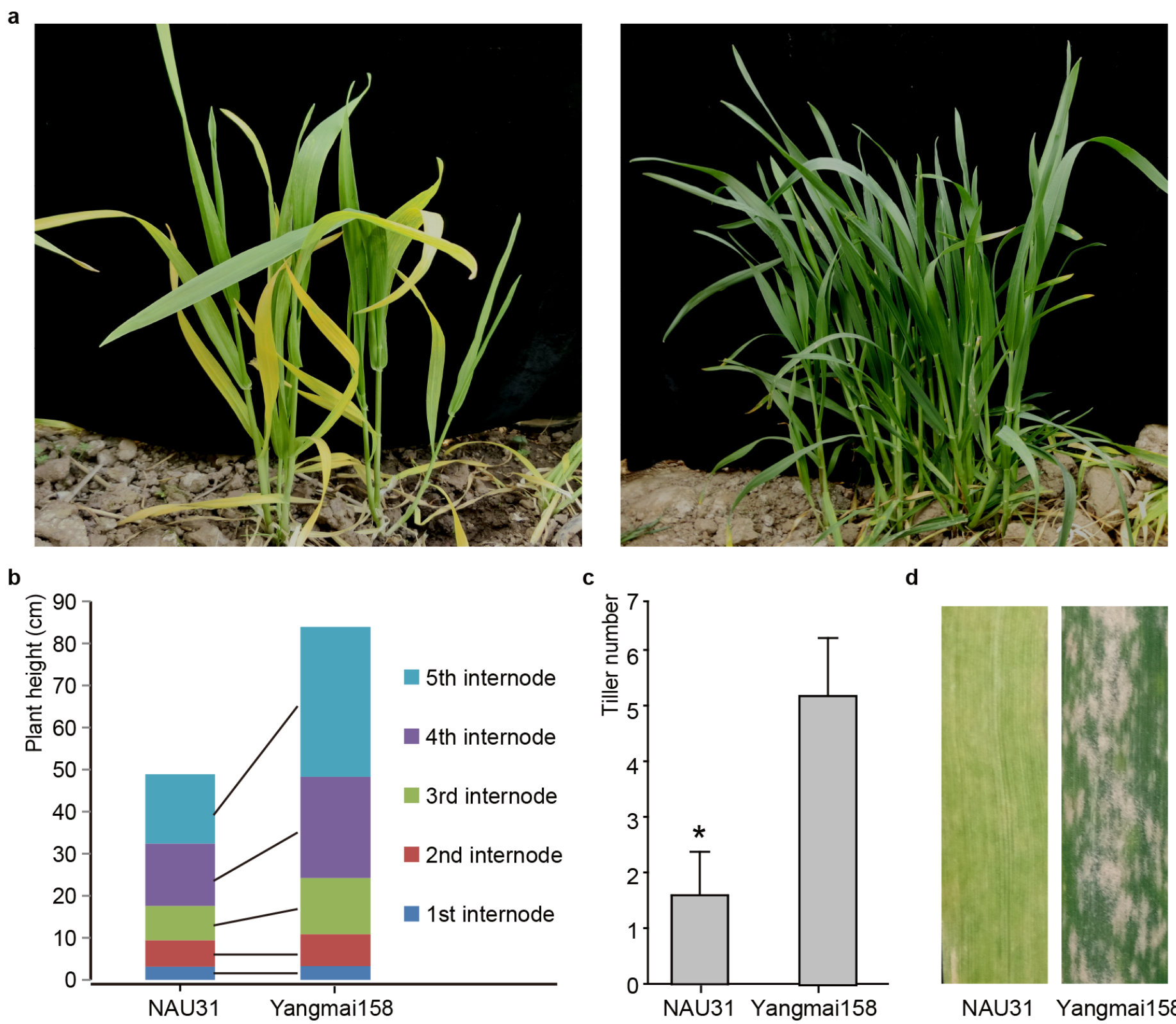

C

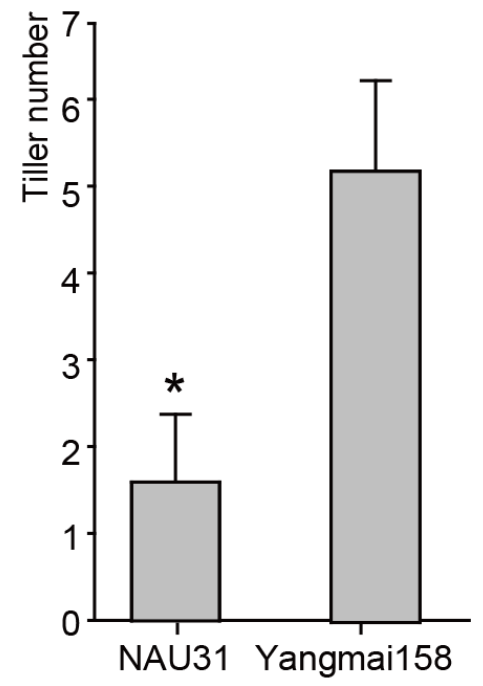

d

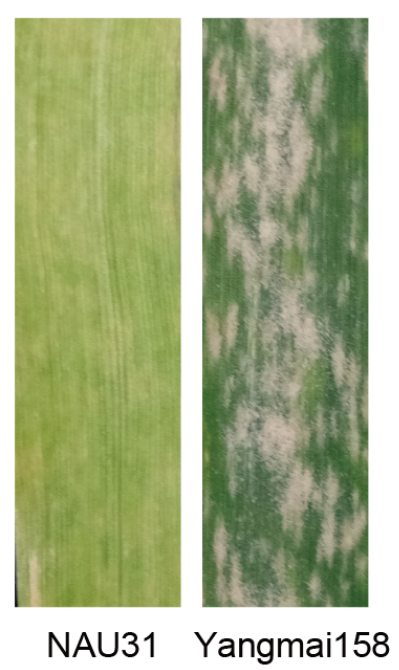

\section{Figure 1}

Comparison of mutant NAU31 (left) and wild-type Yangmai158 (right) for leaf color trait, plant height, tillering number and powdery mildew resistance at mature stage. (a) Morphology of NAU31 and Yangmai158 at seeding stage; (b) Internodes length at mature stage; (c) Tiller number. Significance was 
determined by paired t-tests. $p<0.05$; (d) The hyphae growing on the surface of leaves of NAU31 and Yangmai158 inoculated with powdery mildew isolate E26.

a

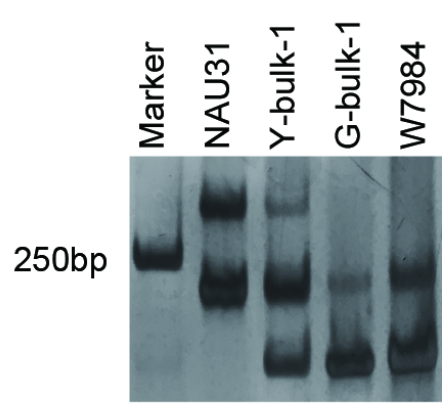

b

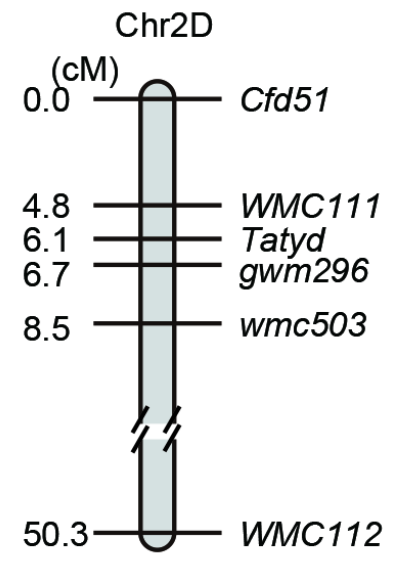

C

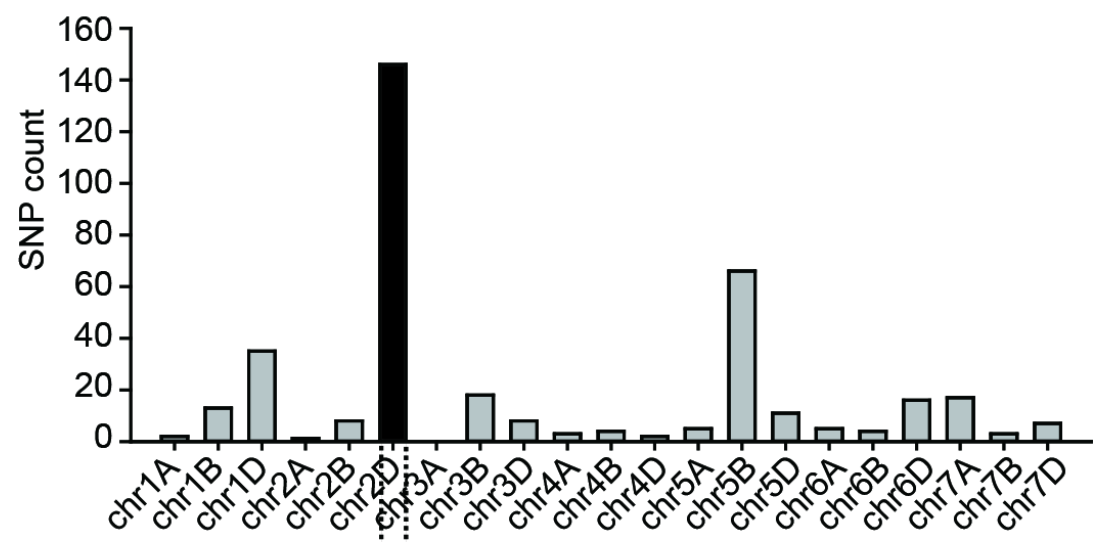

d
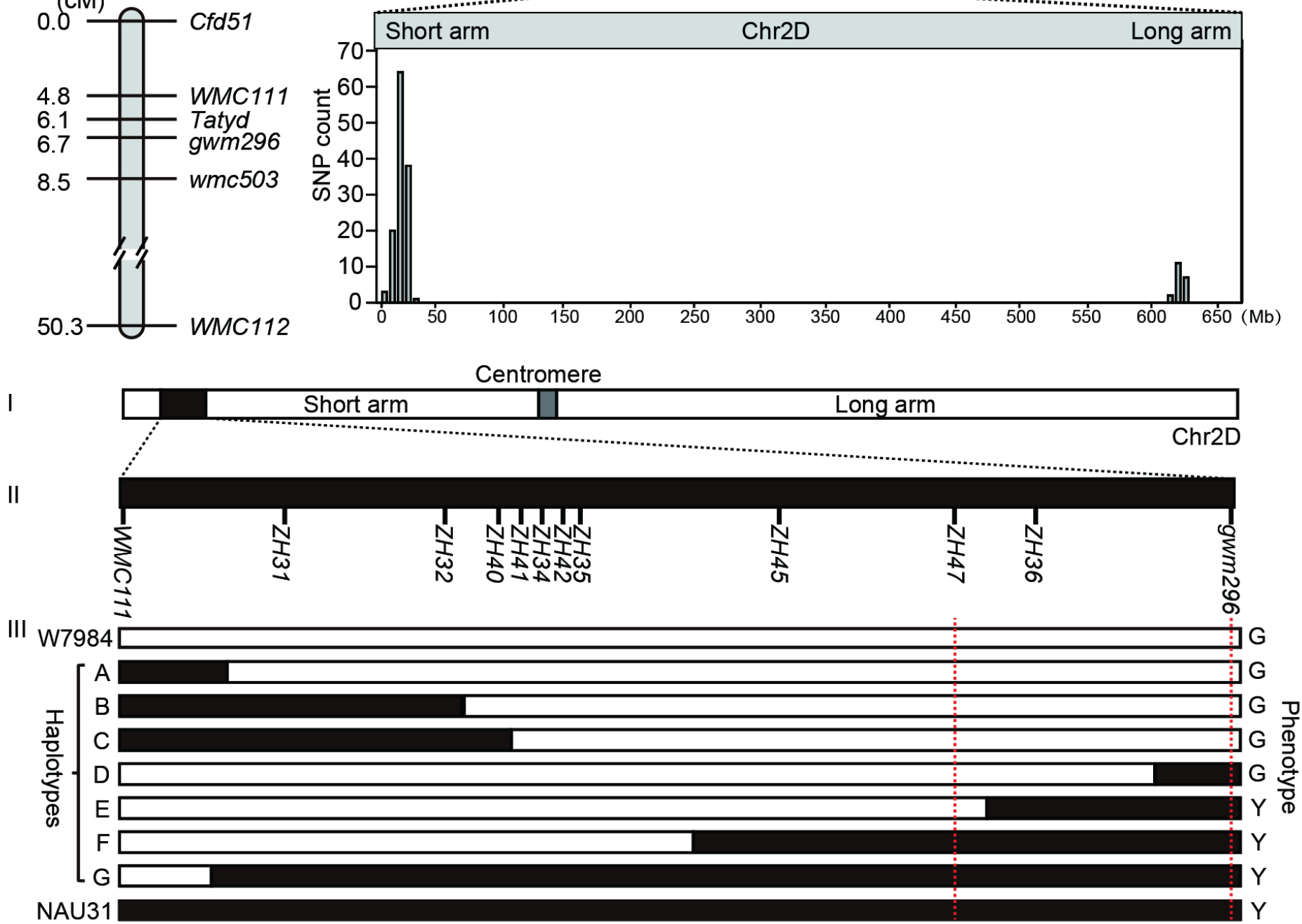

\section{Figure 2}

Mapping of Tatyd. (a) The amplicon of WMC111 with polymorphism between NAU31 and W7984, and Ybulk-1 (yellow DNA bulk) and G-bulk-1 (green DNA bulk); (b) The genetic map at Tatyd region on chromosome 2D; (c) Number of polymorphic SNPs distributed on the wheat chromosomes (top) and wheat chromosomes 2D (bottom); (d) Fine mapping of Tatyd. (I) The 2D chromosome in Yangmai158. 
Gray box indicates the centromere of chromosome 2D, black box indicates the region where the Tatyd was located. (II) The distribution of markers on chromosome 2D, the markers of WMC111 and gwm296 were used for recombinant screening. (III) Recombinants haplotypes classified by marker analysis. Left A to $G$ represent seven recombinant haplotypes by markers analysis; $G$ and $Y$ represent green and yellow leaf color, respectively. Tatyd is mapped between two red dash lines.
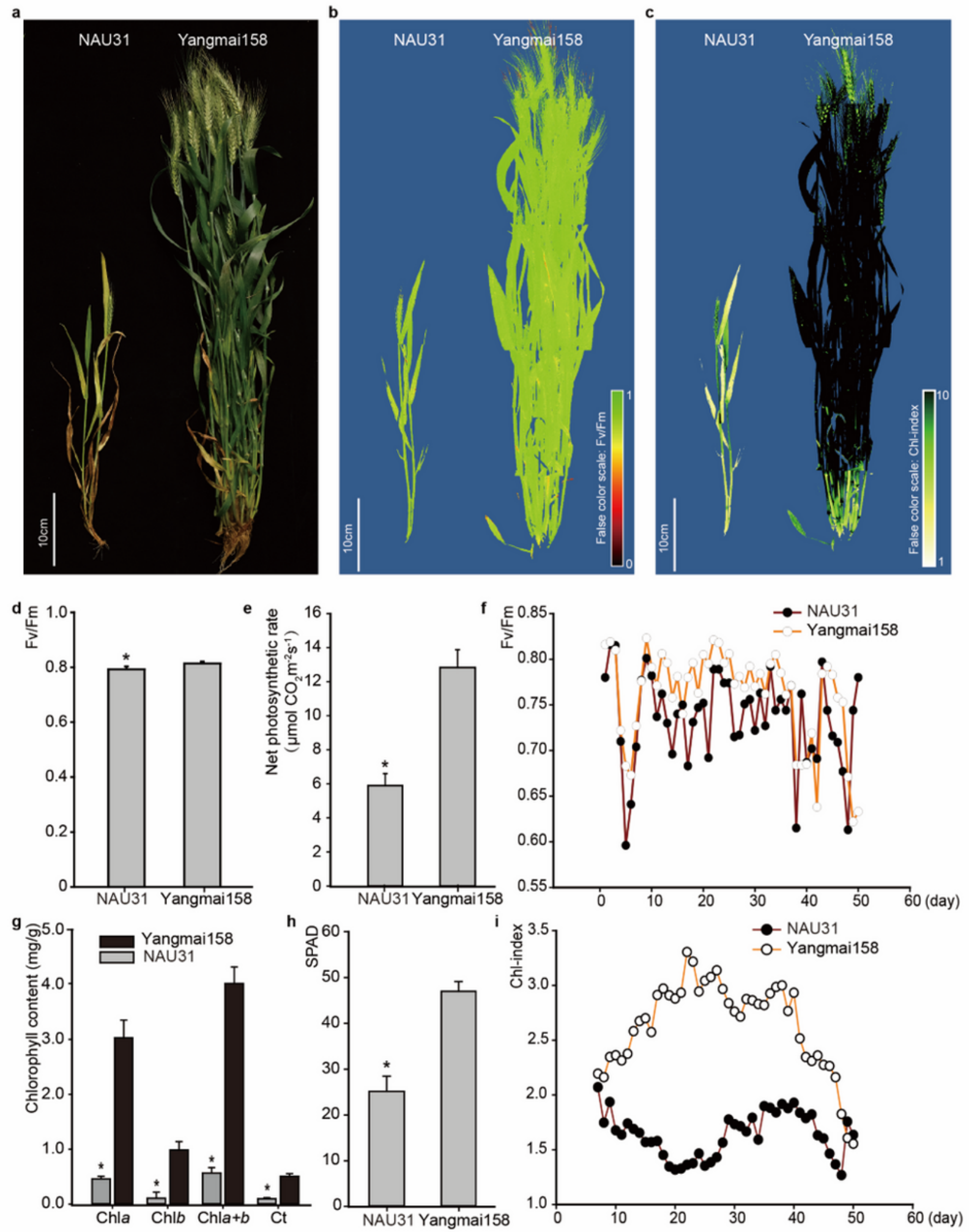

Figure 3 
Comparison of photosynthetic ability between Yangmai158 and NAU31. (a) Visual observation of the plants at mature stage; (b) False-color images of Fv/Fm measurements at mature stage; (c) False-color images of Chl-index measurements at mature stage; (d) Fv/Fm value at mature stage; (e) Net photosynthetic rate at mature stage; (f) Developmental dynamics of Fv/Fm between Yangmai158 and NAU31. (g) Chlorophyll content; (h) SPAD value; (i) Developmental dynamics of Chl-index between Yangmai158 and NAU31. Significance was determined by paired t-tests. $p<0.05$
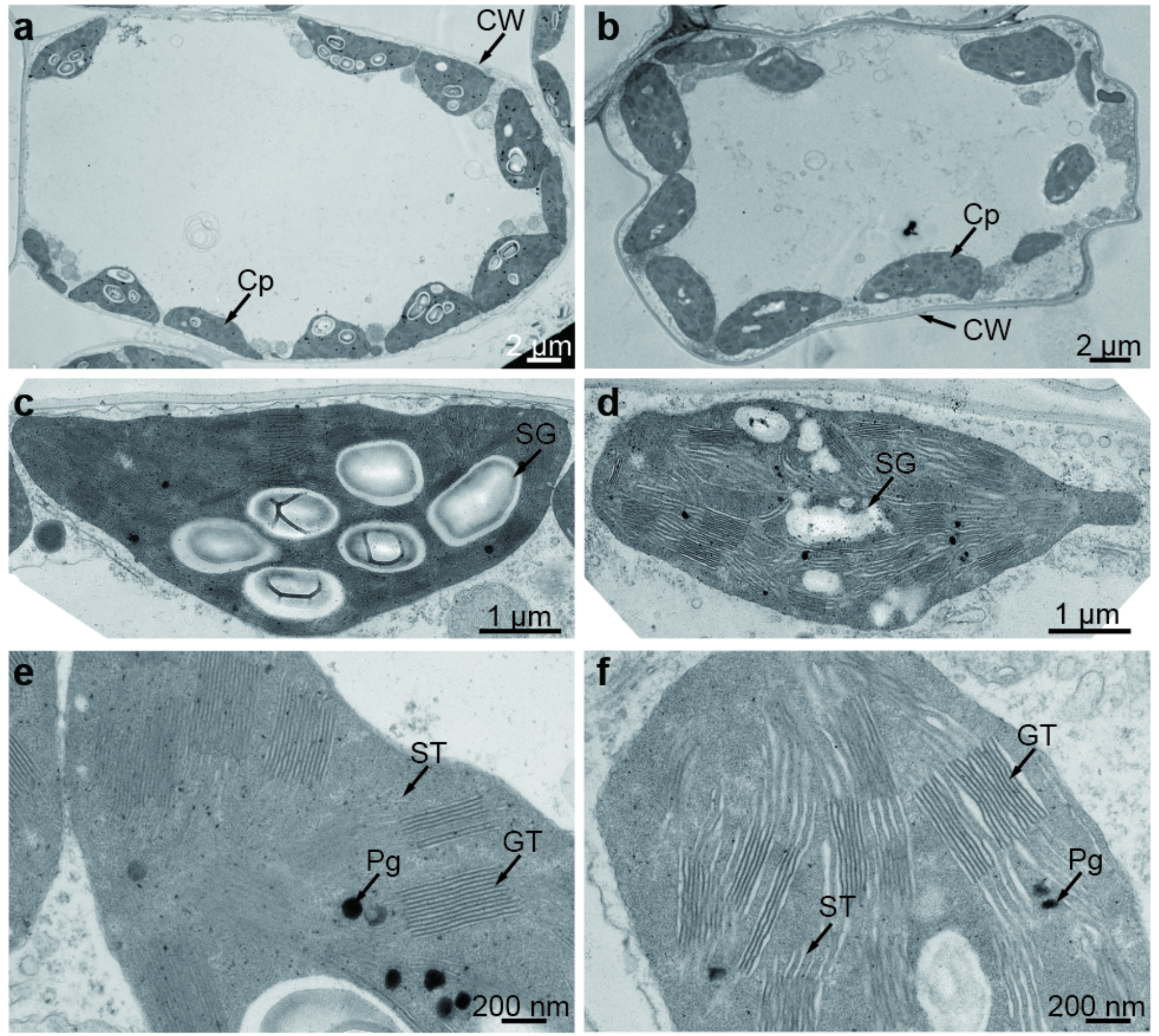

\section{Figure 4}

Transmission electron microscopic analysis of leaf chloroplasts at 2-week growing stage in Yangmai158 and NAU31. Mesophyll cell of Yangmai158 (a) and NAU31 (b); Chloroplasts in mesophyll cell of the Yangmai158 (c) and NAU31 (d); The thylakoid structures in chloroplasts of Yangmai158 (e) and NAU31 
(f). Cp: chloroplast, CW: cell wall, SG: stroma grain, ST: stroma thylakoid, GT: granum thylakoid, Pg: plastoglobuli.

a

NAU31

Yangmai158

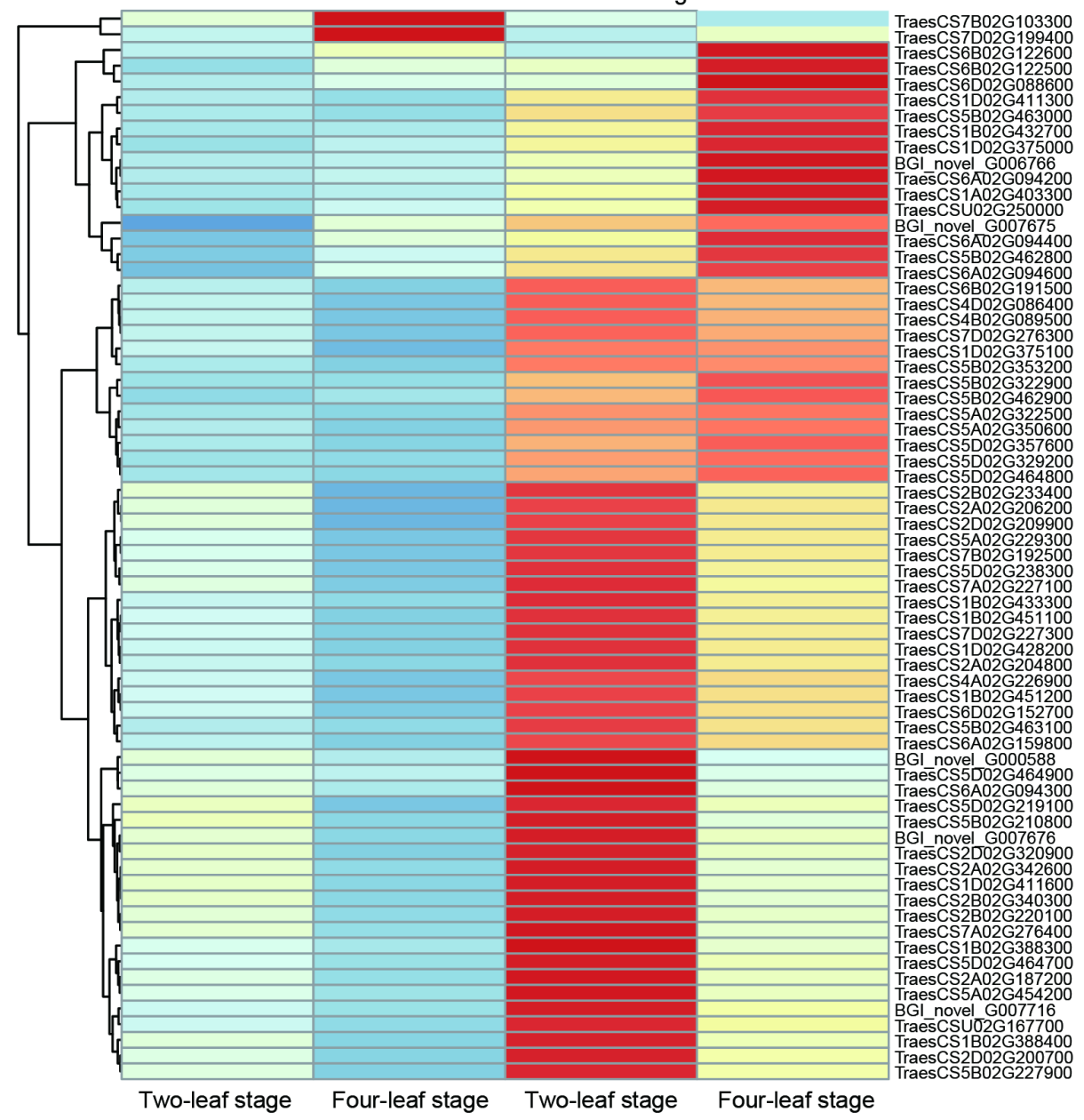

b

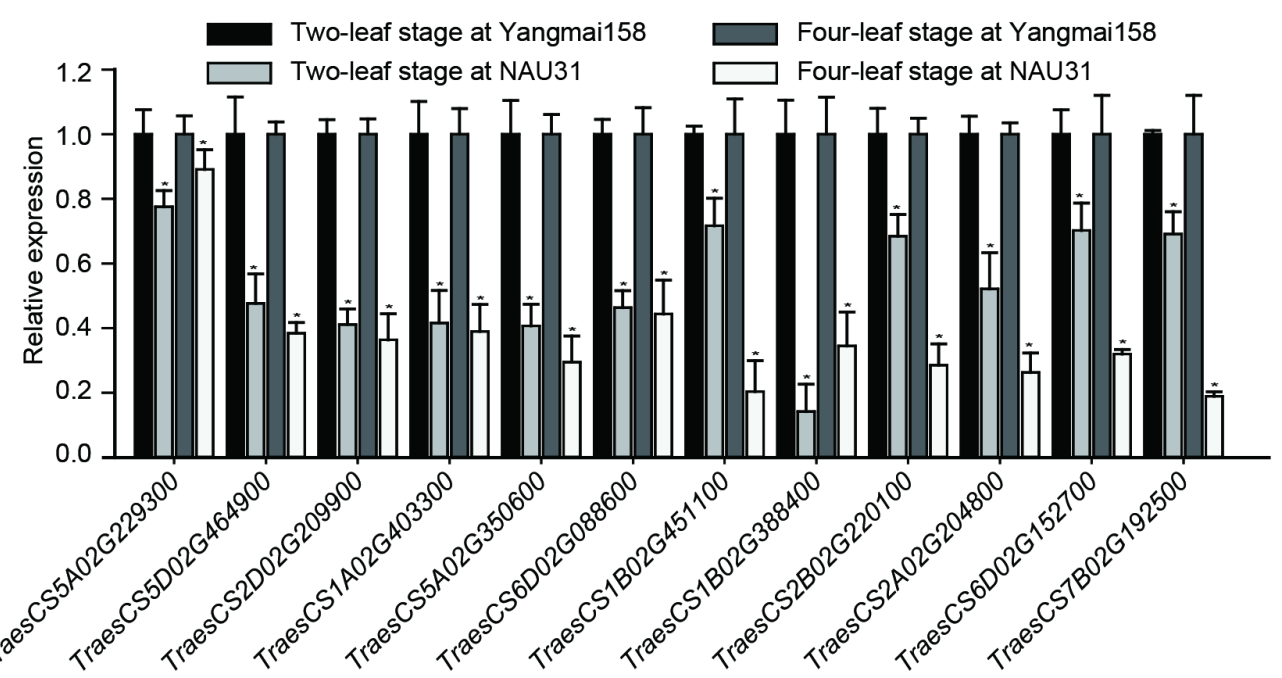

Figure 5

Expression profile for DEGs involved in the Photosynthesis - antenna proteins pathway. (a) Heatmap of photosynthesis - antenna proteins pathway DEGs at two-leaf and four-leaf stages. The expression signal of each gene at each stage is based on Z-score normalization value. (b) qRT-PCR validation of the RNA- 
Seq results for the 12 DEGs in Photosynthesis - antenna proteins pathway. All the expression levels were normalized to tubulin. Yangmai158 is set as "1". Bars indicate standard error (SE), $p<0.05$.

\section{Supplementary Files}

This is a list of supplementary files associated with this preprint. Click to download.

- Additionalfile3.docx

- Additionalfile1.docx

- Additionalfile4.docx

- Additionalfile2.docx

Table 1

Correlation analysis of agronomic traits in the NAU31 $\times$ Yangmai158 $F_{2}$ population.

\begin{tabular}{|llllll|}
\hline & $\begin{array}{l}\text { Leaf } \\
\text { color }\end{array}$ & $\begin{array}{l}\text { Plant } \\
\text { height }\end{array}$ & $\begin{array}{l}\text { Spike } \\
\text { height }\end{array}$ & $\begin{array}{l}\text { Tiller } \\
\text { number }\end{array}$ & $\begin{array}{l}\text { Effective tiller } \\
\text { number }\end{array}$ \\
\hline Leaf color & 1 & & & & \\
\hline Plant height & $0.7409^{* *}$ & 1 & & & \\
\hline Spike height & $0.5217 * *$ & $0.8547^{* *}$ & 1 & & \\
\hline Tiller number & $0.7828^{* *}$ & $0.7722^{* *}$ & $0.6295^{* *}$ & 1 & 1 \\
\hline $\begin{array}{l}\text { Effective tiller } \\
\text { number }\end{array}$ & $0.7982^{* *}$ & $0.7583^{* *}$ & $0.6008^{* *}$ & $0.9868^{* *}$ & 1 \\
\hline ** Represents existing a significant correlation based on Student's t test $(P<0.01)$ & \\
\hline
\end{tabular}

